\title{
The Effect of Respiratory Muscle Training on Aerobic and Anaerobic Strength in Adolescent Taekwondo Athletes
}

\author{
Murat Koç ${ }^{1}$, Nazmi Saritaş ${ }^{2}$ \\ ${ }^{1}$ Sarıçam Sports High School Physical Education and Sports Teacher, Adana, Turkey \\ ${ }^{2}$ Erciyes University Faculty of Sport Sciences, Kayseri, Turkey \\ Correspondence: Nazmi Saritaş, Erciyes University Faculty of Sport Sciences, Kayseri, Turkey.
}

Received: November 12, 2018

Accepted: January 3, 2019 Online Published: January 8, 2019

doi:10.11114/jets.v7i2.3764

URL: https://doi.org/10.11114/jets.v7i2.3764

\begin{abstract}
This study was conducted to investigate the effect of respiratory muscle training on respiratory functions and aerobic and anaerobic strength in adolescent taekwondo athletes. Between the ages of 12-17, 32 taekwondo athletes participated in the study. Participating athletes were randomly divided into two groups as "experimental group" $(\mathrm{n}=15)$ and "control group" $(\mathrm{n}=17)$ as to similar characteristics. The experimental group was given respiratory muscle training for 30 min with an adjustable respiratory pressure device for 3 days a week through 8 weeks period. No exercise was given to the control group with the device. A 20 meter shuttle run test was performed for aerobic capacity and a vertical jump test was performed for anaerobic strength. The inspiratory pressure was measured. After the respiratory muscle training, statistically significant difference was found in the maximum oxygen consumption capacities $\left(\mathrm{MaxVO}_{2}\right)$ and anaerobic strength values $(\mathrm{p}<0.05)$. In the measurements of respiratory function, forced vital capacity (FVC), slow vital capacity (SVC) and maximal voluntary ventilation (MVV), significant difference was found in favor of the experimental group $(\mathrm{p}<0.05)$. In the measurements of inspiration pressure, the results of pressure, strength, flow, volume and energy values were significantly different in favor of the experimental group $(\mathrm{p}<0.05)$. Respiratory muscle training increased the aerobic and anaerobic strength capacity of the experimental group in comparison with the control group. Some of the exercises that were used in the treatment of COPD are thought to facilitate the athletes' respiration control.
\end{abstract}

Keywords: adolescent, taekwondo, rmt, aerobic and anaerobic strength

\section{Introduction}

Today's sports require extensive skills, including physical, technical, mental and tactical features, and require physical athletes to be in optimum condition. Therefore, this is a process that demands more strain (Adigüzel, Karaçam, \& Kırıalt1, 2018). In this process, both the physiological functions and athletic performances of taekwondo athletes are significantly challenged and their optimal development is ensured with different training methods.

Since muscles' need for oxygen increases in physical exercises, respiratory and circulatory systems are expected to adjust to this need physiologically. However, depending on the intensity and time of the exercise, the organism reaches maximal $\mathrm{O}_{2}$ use level $\left(\mathrm{VO}_{2} \mathrm{Max}\right.$ ) after a certain point. At this point of maximum $\mathrm{O}_{2}$ use, $\mathrm{O}_{2}$ use is limited (Fox, Bowers, $\&$ Foss, 1999). The accumulation of metabolites such as lactic acid increases muscle fatigue and causes the exercise to be finished earlier by affecting the afferent nerve system from the brain. In the studies conducted to prevent performance decrease, it was stated that respiratory muscle training increases the strength of the inspiratory muscles in order to increase exercise tolerance and it is efficient in retarding respiratory muscle fatigue (Scherer, Spengler, Owassapian, Imhof, \& Boutellier, 2000).

Respiratory muscle training was first used for patients and then for healthy individuals in order to increase respiratory muscle functions (Padula \& Yeaw, 2007). Respiratory muscle trainings are accepted as ergogenic support in terms of athletic performance. This support is improved with different training methods (McConnell \& Romer, 2004).

As with most individual and team sports, taekwondo sports also requires a high level of aerobic and anaerobic physical fitness (Adigüzel NS., and Günay M, 2016). Attacks to the opponent in taekwondo competitions last $1-5$ seconds. Since the attack is intense, anaerobic metabolism is dominant. Taekwondo is accepted as a series of intermittent aerobic and anaerobic exercises (Thompson \& Vinueza, 1991). Competitions are not at the same level continuously. During the 
competition, the performances and energy density of the taekwondo athletes may change depending on their stress, motivation, tactics and the performance of the opponent (Bouhlel, et all., 2006). However, respiratory muscle training is needed for this adaptation to develop, to continue for longer time and to increase the competition performance.

It has not been considered that the ability of maintaining a high level of ventilation plays an important role in restricting maximal aerobic capacity in healthy individuals (Powers \& Criswell, 1996). It was stated that highly intensive respiratory muscle training decreases respiratory distress in well trained individuals, and it partly increases maximum oxygen consumption in healthy and trained individuals (Chatham, Baldwin, Griffiths, Summers, \& Enright, 1999).

Respiratory muscle training is identified in order to remove the respiration restrictions emerging in continued high intensity exercises of healthy individuals. Since respiratory muscle training increases the performance of endurance exercises, this training type is carried out to increase the workout and competition performance of the athletes (Illi, Held, Frank, \& Spengler, 2012).

It was revealed that in studies in which respiratory muscle training has been performed, endurance was improved. The emergence of these improvements change depending on the type of the workout. It has been shown that respiratory muscle strength and respiratory muscle endurance are more obvious in well trained athletes. Therefore, respiratory muscle functions are known to have a potential function in individuals having heavy physical exercises (Pine \& Watsford, 2005).

Studies on respiratory muscle training are usually aimed at middle and old age groups (Balbaloğlu, 2015). However, respiratory muscles are also important to adolescents for performance as well as adults. This study was conducted to investigate the effect of respiratory muscle training on respiratory functions and aerobic and anaerobic strength in adolescent taekwondo athletes.

\section{Materials and Methods}

This study is an experimental study. By receiving necessary permissions, it was conducted in Kayseri Emniyet Sports Club between the period of 15 March-15 May 2017.

Taekwondo athletes (32 in number) between the ages of 12-17 participated in the research voluntarily. The athletes were divided into two groups randomly as having similar characteristics. There were $(n=15)$ athletes in the experimental group and $(\mathrm{n}=17)$ athletes in the control group. The participants joined training program which was aimed at the branch. In addition to these workouts, the experimental group had respiratory muscle training with a respiratory muscle training device that has adjustable pressure level. The training was performed for $30 \mathrm{~min}$, three days a week for 8 weeks. In addition to the respiratory muscle training, pursed lips respiratory exercises, which are used for COPD rehabilitation program, were also performed. The control group did not have any respiratory muscle training. During the respiratory muscle training and lung volume capacities measurements, oxygen saturation of the athletes was checked. When oxygen saturation decreased to below $90 \%$, respiratory muscle training and lung volume capacity measurements were interrupted until normal levels of oxygen saturation were reached. Before the training, at the end of the 4th and 8th weeks, respectively, lung volume and capacities were measured at three different times. The measurements were performed in a sitting position on the chair by using a Cosmed Pony FX spirometer. A 20-meter shuttle run test was performed for maximum aerobic strength measurement. The values of the athletes were marked on the 20-meter measurement form and the $\mathrm{VO}_{2} \mathrm{Max}$ values of the athletes were determined in $\mathrm{ml} / \mathrm{kg} / \mathrm{min}$. Vertical jump test was performed to determine the anaerobic strength, and anaerobic strength was calculated by Lewis formula. The athletes were made to sit on a chair for inspiratory pressure measurements, their noses were closed by pegs and respiration was provided with Power Breathe K5 manual device. Oxygen saturation and heart rate were determined from the left index finger of the athletes with pulse oximeter device. The statures of the subjects $(\mathrm{cm})$ were measured as they were barefooted, and the soles of their feet were on the floor, ankles were contiguous, knees were stiff and bodies were at upright position; by using a meter with the $1 \mathrm{~cm}$ degree of precision.

The body weights of participants were measured barefooted and with minimal clothes by using a bascule with 0.1 degree of precision. Body fat percentage, body fat mass, lean body mass and total body fluid were measured by using Tanita TBF-300 at $100 \mathrm{~g}$ sensitivity and with light clothing as much as possible. Body mass index (BMI) was calculated by dividing the body weight $(\mathrm{kg})$ by the square of the height $\left(\mathrm{m}^{2}\right)$.

\subsection{Statistical Analysis}

SPSS 20.0 was used for the analysis of the data. Shapiro-Wilk test was used as the normality test of the distributions. Distributions were found to be normal. Arithmetic mean and standard deviation were revealed as the descriptive statistics. Two-way analysis of variance was used as a statistical comparison test and variance analysis was used in repetitive measurements in order to see changes in the data with significant interaction. Bonferroni test among multiple comparison tests was used. Paired comparisons of control and experimental groups in each time were done by $\mathrm{t}$ test in independent groups. Significance level was taken as $\mathrm{p}<0.05$. 


\section{Results}

There was a statistically significant difference in time factor between two groups on body weight and BMI in the measurement of physical characteristics of 8 weeks respiratory muscle training $(\mathrm{p}<0.05)$. According to the results of the multiple comparison of the main effects over time, body weight at the first time $(\mathrm{kg})$ was found to be significantly lower than the second and third times ( $\mathrm{p}<0.05)$. No statistical difference was found in height, fat and fat mass ( $\mathrm{p}>0.05)$, (Table 1$)$.

Table 1. Comparison of the physical characteristics of the taekwondo athletes.

\begin{tabular}{|c|c|c|c|c|c|c|c|c|c|}
\hline \multirow[t]{2}{*}{ Variable } & & \multirow{2}{*}{$\begin{array}{c}\begin{array}{c}\text { Experiment } \\
(\mathbf{n}=15)\end{array} \\
\overline{\mathbf{X}} \pm \text { SD }\end{array}$} & \multirow{2}{*}{$\begin{array}{c}\begin{array}{c}\text { Control } \\
(\mathbf{n}=17)\end{array} \\
\overline{\mathbf{X}} \pm \text { SD } \\
\end{array}$} & \multicolumn{2}{|c|}{ Group } & \multicolumn{2}{|c|}{ Time } & \multicolumn{2}{|c|}{$\begin{array}{l}\text { Group*Time } \\
\text { (Interaction) }\end{array}$} \\
\hline & & & & $\mathbf{F}$ & $\mathbf{p}$ & $\mathbf{F}$ & $\mathbf{p}$ & $\mathbf{F}$ & $\mathbf{p}$ \\
\hline Age (Year) & Previously & $14.73 \pm 1.44$ & $13.94 \pm 1.20$ & & & & & & \\
\hline Height $(\mathrm{cm})$ & Previously & $164.60 \pm 8.74$ & $160.41 \pm 9.23$ & & & & & & \\
\hline \multirow{3}{*}{ Body weight (kg) } & Previously & $53.57 \pm 10.14$ & $48.48 \pm 8.79$ & \multirow{3}{*}{2.801} & \multirow{3}{*}{0.105} & \multirow{3}{*}{15.422} & \multirow{3}{*}{$<0.001$} & \multirow{3}{*}{1.636} & \multirow{3}{*}{0.205} \\
\hline & 4th Week & $54.76 \pm 9.67$ & $48.85 \pm 8.86$ & & & & & & \\
\hline & 8th Week & $55.00 \pm 9.42$ & $49.52 \pm 8.97$ & & & & & & \\
\hline \multirow{3}{*}{ BMI $\left(\mathrm{kg} / \mathrm{m}^{2}\right)$} & Previously & $19.66 \pm 2.38$ & $18.69 \pm 2.16$ & \multirow{3}{*}{2.068} & \multirow{3}{*}{0.161} & \multirow{3}{*}{14.229} & \multirow{3}{*}{$<0.001$} & \multirow{3}{*}{1.552} & \multirow{3}{*}{0.222} \\
\hline & 4th Week & $20.10 \pm 2.19$ & $18.83 \pm 2.16$ & & & & & & \\
\hline & 8th Week & $20.22 \pm 2.06$ & $19.06 \pm 2.21$ & & & & & & \\
\hline \multirow{3}{*}{ Body fat (\%) } & Previously & $13.79 \pm 5.98$ & $15.96 \pm 8.24$ & \multirow{3}{*}{0.898} & \multirow{3}{*}{0.351} & \multirow{3}{*}{0.502} & \multirow{3}{*}{0.549} & \multirow{3}{*}{0.999} & \multirow{3}{*}{0.353} \\
\hline & 4th Week & $13.50 \pm 6.29$ & $14.41 \pm 7.28$ & & & & & & \\
\hline & 8th Week & $12.84 \pm 5.77$ & $16.46 \pm 9.40$ & & & & & & \\
\hline \multirow{3}{*}{$\begin{array}{l}\text { Body } \\
(\mathrm{kg})\end{array}$} & Previously & $7.27 \pm 3.60$ & $8.15 \pm 4.87$ & \multirow{3}{*}{0.354} & \multirow{3}{*}{0.556} & \multirow{3}{*}{1.027} & \multirow{3}{*}{0.362} & \multirow{3}{*}{0.129} & \multirow{3}{*}{0.873} \\
\hline & 4th Week & $6.67 \pm 3.64$ & $7.08 \pm 4.25$ & & & & & & \\
\hline & 8th Week & $7.15 \pm 3.66$ & $8.19 \pm 5.04$ & & & & & & \\
\hline
\end{tabular}

When Group x Time interaction is significant, multiple comparison test result is expressed by alphabetical symbol. There is no difference between the measurements having the same alphabetical symbols in the same column and having the same letter $* * * \mathrm{p}<0.001 * * \mathrm{p}<0.01 * \mathrm{p}<0.05$; \#: difference between the groups. BMI: Body Mass Index

Respiratory muscle training has an effect on the anaerobic strength $(\mathrm{F}=4.622 ; \mathrm{p}<0.05)$. In testing period, there were significant increases in anaerobic strength in both groups $(\mathrm{F}=34.606 ; \mathrm{p}<0.05)$. As a result of the respiratory muscle training, the changes in the anaerobic strength were significantly higher in experimental and control groups $(\mathrm{F}=5.813$; $\mathrm{p}<0.05$ ), (Table 2).

A statistically significant difference was found in group and time factors in terms of maximum oxygen consumption $\left(\mathrm{VO}_{2} \max \right)(\mathrm{p}<0.05)$. According to the multiple comparison result of the main effects of time, the first time was found to be significantly lower than the second time $(p<0.05)$. There was no difference between the second and third times measurements ( $>0.05)$. In the comparison of the measurements of the experimental and control groups at each time, there was no difference ( $>>0.05)$. $\mathrm{MaxVO}_{2}$ of the experimental group was significantly higher than the control group in the third measurement $(\mathrm{p}<0.05)$. No significant change in pulse and $\mathrm{SpO}_{2}$ values was observed ( $\left.\mathrm{p}>0.05\right)$, (Table 2).

Table 2. Comparison of the physical characteristics of the taekwondo athletes.

\begin{tabular}{|c|c|c|c|c|c|c|c|c|c|}
\hline \multirow[t]{2}{*}{ Variable } & & \multirow{2}{*}{$\begin{array}{l}\begin{array}{l}\text { Experiment } \\
(\mathbf{n}=\mathbf{1 5})\end{array} \\
\overline{\mathbf{X}} \pm \text { SD }\end{array}$} & \multirow{2}{*}{$\begin{array}{r}\begin{array}{r}\text { Control } \\
(\mathbf{n}=17)\end{array} \\
\overline{\mathbf{X}} \pm \mathbf{S D}\end{array}$} & \multicolumn{2}{|c|}{ Group } & \multicolumn{2}{|c|}{ Time } & \multicolumn{2}{|c|}{$\begin{array}{l}\text { Group*Time } \\
\text { (Interaction) }\end{array}$} \\
\hline & & & & $\mathbf{F}$ & $\mathbf{P}$ & $\mathbf{F}$ & $\mathbf{P}$ & $\mathbf{F}$ & $\mathbf{p}$ \\
\hline \multirow{3}{*}{$\begin{array}{l}\text { Anaerobic } \\
\text { Strength (Watt) }\end{array}$} & Previously & $72.77 \pm 16.74^{\mathrm{a}}$ & $63.10 \pm 14.94^{\mathrm{a}}$ & \multirow{3}{*}{4.622} & \multirow{3}{*}{0.040} & \multirow{3}{*}{34.606} & \multirow{3}{*}{0.001} & \multirow{3}{*}{5.813} & \multirow{3}{*}{0.005} \\
\hline & 4th Week & $77.52 \pm 17.08^{b}$ & $65.53 \pm 15.69^{b} \#$ & & & & & & \\
\hline & 8th Week & $81.14 \pm 16.75^{\mathrm{c}}$ & $66.58 \pm 15.15^{b} \#$ & & & & & & \\
\hline \multirow{3}{*}{$\begin{array}{l}\mathrm{MaxVO}_{2} \\
(\mathrm{ml} / \mathrm{kg} / \mathrm{min})\end{array}$} & Previously & $31.89 \pm 5.26$ & $29.12 \pm 5.75$ & \multirow{3}{*}{4.418} & \multirow{3}{*}{0.044} & \multirow{3}{*}{4.721} & \multirow{3}{*}{0.021} & \multirow{3}{*}{0.463} & \multirow{3}{*}{0.579} \\
\hline & 4th Week & $34.06 \pm 4.40$ & $30.92 \pm 5.31$ & & & & & & \\
\hline & 8th Week & $34.75 \pm 5.30$ & $30.55 \pm 4.94 \#$ & & & & & & \\
\hline \multirow{3}{*}{ Pulse (beat/min) } & Previously & $83.20 \pm 9.50$ & $80.29 \pm 7.64$ & \multirow{3}{*}{0.505} & \multirow{3}{*}{0.483} & \multirow{3}{*}{1.929} & \multirow{3}{*}{0.163} & \multirow{3}{*}{0.497} & \multirow{3}{*}{0.572} \\
\hline & 4th Week & $80.53 \pm 8.18$ & $79.65 \pm 7.15$ & & & & & & \\
\hline & 8th Week & $82.73 \pm 7.85$ & $81.06 \pm 7.47$ & & & & & & \\
\hline \multirow{3}{*}{$\mathrm{SpO}_{2}(\%)$} & Previously & $97.47 \pm 1.06$ & $97.71 \pm 0.92$ & \multirow{3}{*}{0.295} & \multirow{3}{*}{0.591} & \multirow{3}{*}{1.261} & \multirow{3}{*}{0.291} & \multirow{3}{*}{0.875} & \multirow{3}{*}{0.420} \\
\hline & 4th Week & $97.60 \pm 0.83$ & $97.88 \pm 1.05$ & & & & & & \\
\hline & 8th Week & $97.80 \pm 0.68$ & $97.76 \pm 1.03$ & & & & & & \\
\hline
\end{tabular}

When Group x Time interaction is significant, multiple comparison test result is expressed by alphabetical symbol. There is no difference between the measurements having the same alphabetical symbols in the same column and having the same letter $* * * \mathrm{p}<0.001 * * \mathrm{p}<0.01 * \mathrm{p}<0.05$; \#: difference between the groups. $\mathrm{MaxVO}_{2}$ : Maximum oxygen consumption, $\mathrm{SpO}_{2}$ : Oxygen saturation.

A statistically significant difference was found in the main effect of time on the forced vital capacity (FVC) and in the group-time interaction, $(\mathrm{F}=5.143 ; \mathrm{p}=0.009 ; \mathrm{F}=3.322 ; \mathrm{p}=0.044)$. According to the multiple comparison test result of the 
main effects of time, significant differences occurred in the direction of increase between the second and third measurements in the probable paired comparisons $(\mathrm{p}<0.05)$. According to the multiple comparison result of the experimental group, the third measurement was found to be significantly different from the first and second measurements, since the group-time interaction was significant $(\mathrm{p}<0.05)$. No significant difference was found in the forced vital capacity (liter) measurements of the control group ( $>0.05$ ). The main effects between the groups was not statistically significant $(\mathrm{F}=1.322 ; \mathrm{p}=0.259)$. However, while no difference was found between the first and the second measurements in the comparisons of the measurements of the experimental and control groups at each time ( $p>0.05)$, the forced vital capacity of the experimental group was observed to be higher than the control group in the third measurements $(\mathrm{p}<0.05)$, (Table 3$)$.

The effect of time on the volume of the air that was exhaled at the 1st second of the forced expiration (FEV1) and group-time interaction $(\mathrm{F}=3.437 ; \mathrm{p}=0.044 ; \mathrm{F}=4.179 ; \mathrm{p}=0.024)$ was found to be statistically significant. According to the multiple comparison test result of the main effects of time, the third measurement was found to be significantly different from the second measurement in the probable paired comparisons $(\mathrm{p}<0.05)$. According to the multiple comparison result of the experimental group, in all the probable paired comparison of the forced vital capacity (liter) of the experimental group, the third measurement was found to be significantly difference from the first and second measurements $(\mathrm{p}<0.05)$, since the group-time interaction was significant. No statistically significant difference was found in the control group $(p>0.05)$. The difference between the groups was not statistically significant $(F=2.438 ; p=0.129)$. While no difference was observed between the first and the second measurements in the comparisons of the measurements of experimental and control groups at each time $(p>0.05)$, it was seen in the third measurements that the forced vital capacity of the experimental group was significantly higher than the control group ( $\mathrm{p}<0.05)$, (Table 3$)$.

No difference was observed in IRV and ERV values in the slow vital capacity (SVC) measurements after the respiratory muscle training ( $p>0.05$ ). A significant difference occurred in the respiration minute ventilation (VE) the main effect of time $(\mathrm{F}=4.441 ; \mathrm{p}=0.016)$. No statistical difference was observed between the groups and group-time interaction $(\mathrm{F}=0.332 ; \mathrm{p}=0.634 ; \mathrm{F}=0.651 ; \mathrm{p}=0.525)$. According to the multiple comparison test of the main effects in time, $\mathrm{VE}$ in the first and second times (liter/min) was found to be significantly higher than the third time $(\mathrm{p}<0.05)$ (Table 3$)$.

A significant difference was observed in the main effect of the group and time on the maximum voluntary ventilation (MVV) $(\mathrm{F}=4.928 ; \mathrm{p}=0.034 ; \mathrm{F}=3.701 ; \mathrm{p}=0.042)$. There was no statistically significant difference in the group-time interaction $(\mathrm{F}=1.235 ; \mathrm{p}=0.292)$. A statistically significant difference occurred between the experimental group and the control group, since the main effect between the groups was significant $(p<0.05)$. While the main effect of time was statistically significant $(\mathrm{p}<0.05)$, there was no significant difference in each time unit $(\mathrm{p}>0.05)$ (Table 3$)$.

Depending on the strength of the inspiratory muscles during the exercise session, the main effects of the group and time on the average pressure (Pressure Avg.) produced in the respiratory track ( $\mathrm{F}=5.058 ; \mathrm{p}=0.032 ; \mathrm{F}=11.805 ; \mathrm{p}=0.001$ ) were statistically significant, but the group-time interaction $(\mathrm{F}=0.271 ; \mathrm{p}=0.755)$ was not statistically significant. According to the multiple comparison result of the main effects of time, the first time was observed to be significantly lower than the third time $(\mathrm{p}<0.05)$. While no significant difference was observed in the first time in the comparison of the measurements of the experimental and control groups at each time $(\mathrm{p}>0.05)$, the Pressure Avg. $\left(\mathrm{cmH}_{2} \mathrm{O}\right)$ of the experimental group in the second and third times was found to be significantly higher when compared to the control group (p<0.05), (Table 3).

When Group x Time interaction is significant, multiple comparison test result is expressed by alphabetical symbol. There is no difference between the measurements having the same alphabetical symbols in the same column and having the same letter ***p $<0.001 * * \mathrm{p}<0.01 * \mathrm{p}<0.05$; \#: difference between the groups. FVC: Forced Vital Capacity, FEV1: The volume of the air exhaled at the 1st second of the forced expiration. ERV: Expiration Residual Volume, IRV: Inspiration Residual Volume, VE: Respiration Minute Ventilation. MVV: Maximum Voluntary Ventilation. Pressure Avg: The average pressure produced in the respiratory track depending on the strength of the inspiration muscles during the exercise session. 
Table 3. The comparison of the forced vital capacity, slow vital capacity, the maximum voluntary ventilation and the inspiration pressure measurements of the taekwondo athletes.

\begin{tabular}{|c|c|c|c|c|c|c|c|c|c|}
\hline \multirow[t]{2}{*}{ Variable } & & \multirow{2}{*}{$\begin{array}{l}\text { Experiment }(\mathbf{n}=\mathbf{1 5}) \\
\overline{\mathbf{x}} \pm \text { SD }\end{array}$} & \multirow{2}{*}{$\begin{array}{c}\begin{array}{r}\text { Control } \\
(\mathbf{n}=17)\end{array} \\
\overline{\mathbf{x}} \pm \text { SD } \\
\end{array}$} & \multicolumn{2}{|c|}{ Group } & \multicolumn{2}{|c|}{ Time } & \multicolumn{2}{|c|}{ Group*Time (Interaction) } \\
\hline & & & & $\mathbf{F}$ & $\mathbf{p}$ & $\mathbf{F}$ & $\mathbf{P}$ & $\mathbf{F}$ & $\mathbf{p}$ \\
\hline \multirow{3}{*}{$\mathrm{FVC}(\mathrm{L})$} & Previously & $4.14 \pm 0.83^{\mathrm{a}}$ & $3.97 \pm 1.19$ & \multirow{3}{*}{1.322} & \multirow{3}{*}{0.259} & \multirow{3}{*}{5.143} & \multirow{3}{*}{0.009} & \multirow{3}{*}{3.322} & \multirow{3}{*}{0.044} \\
\hline & 4th Week & $3.95 \pm 1.17^{\mathrm{a}}$ & $3.91 \pm 0.87$ & & & & & & \\
\hline & 8th Week & $4.85 \pm 1.08^{b}$ & $4.02 \pm 0.82 \#$ & & & & & & \\
\hline \multirow{3}{*}{ FEV1 (L) } & Previously & $3.69 \pm 0.78^{\mathrm{a}}$ & $3.57 \pm 1.13$ & \multirow{3}{*}{2.438} & \multirow{3}{*}{0.129} & \multirow{3}{*}{3.437} & \multirow{3}{*}{0.044} & \multirow{3}{*}{4.179} & \multirow{3}{*}{0.024} \\
\hline & 4th Week & $3.72 \pm 0.83^{\mathrm{a}}$ & $3.49 \pm 0.76$ & & & & & & \\
\hline & 8th Week & $4.37 \pm 0.97^{b}$ & $3.50 \pm 0.65 \#$ & & & & & & \\
\hline \multirow{3}{*}{ ERV (L) } & Previously & $1.40 \pm 0.32$ & $1.66 \pm 0.49$ & \multirow{3}{*}{0.407} & \multirow{3}{*}{0.528} & \multirow{3}{*}{1.830} & \multirow{3}{*}{0.183} & \multirow{3}{*}{1.797} & \multirow{3}{*}{0.188} \\
\hline & 4th Week & $2.02 \pm 1.57$ & $1.67 \pm 0.64$ & & & & & & \\
\hline & 8th Week & $1.90 \pm 0.46$ & $1.66 \pm 0.33$ & & & & & & \\
\hline \multirow{3}{*}{ IRV (L) } & Previously & $1.47 \pm 0.76$ & $2.00 \pm 3.09$ & \multirow{3}{*}{0.006} & \multirow{3}{*}{0.940} & \multirow{3}{*}{0.972} & \multirow{3}{*}{0.341} & \multirow{3}{*}{1.055} & \\
\hline & 4th Week & $1.56 \pm 0.62$ & $1.38 \pm 0.97$ & & & & & & 0.320 \\
\hline & 8th Week & $2.16 \pm 0.73$ & $1.73 \pm 0.82$ & & & & & & \\
\hline & Previously & $21.01 \pm 8.35$ & $23.67 \pm 7.50$ & & & & & & \\
\hline $\mathrm{VE}(\mathrm{L} / \mathrm{min})$ & 4th Week & $19.80 \pm 7.50$ & $19.37 \pm 8.34$ & 0.332 & 0.634 & 4.441 & 0.016 & 0.651 & 0.525 \\
\hline & 8th Week & $17.97 \pm 6.09$ & $18.76 \pm 6.21$ & & & & & & \\
\hline & Previously & $142.51 \pm 31.45$ & $130.55 \pm 38.87$ & & & & & & \\
\hline MVV (L/min) & 4th Week & $149.93 \pm 40.98$ & $124.42 \pm 30.88$ & 4.928 & 0.034 & 3.701 & 0.042 & 1.235 & 0.298 \\
\hline & 8th Week & $178.54 \pm 73.72$ & $138.01 \pm 39.19$ & & & & & & \\
\hline & Previously & $21.74 \pm 5.79$ & $17.75 \pm 7.47$ & & & & & & \\
\hline Pressure S.Avg. & 4th Week & $24.32 \pm 5.57$ & $19.25 \pm 6.95 \#$ & 5.058 & 0.032 & 11.805 & $<0.001$ & 0.271 & 0.755 \\
\hline (C) & 8th Week & $26.11 \pm 6.33$ & $21.17 \pm 5.99 \#$ & & & & & & \\
\hline
\end{tabular}

\section{Discussion}

The athletes that participated in the study are classified as adolescent by WHO due to their age range, and physical development of the body occurs during this period (Spear, 2002). It is considered that the increase in the body weights of the athletes after the measurement was due to the adolescent period. The respiratory muscle training of the experimental group made them to consume more energy than the control group. When Stamford's principle which states that, "burning high amount of calorie during workouts causes a decrease in the body fat percentage" was taken into consideration, the values obtained from this study confirmed the principle (Stamford, 1983). According these results, a statistically significant difference emerged in the lean body masses, BMIs and total body fluid of the athletes due to the spending of more energy.

It was determined that respiratory muscle training that lasted for 8 weeks significantly increased anaerobic strength in the adolescent athletes. The anaerobic strength increase of the group that participated in the respiratory muscle training was much higher than the control group. In the literature, there is no study on the effect of respiratory muscle training on anaerobic strength in this age group, but there is limited number of studies in older age groups. It was reported that 6 weeks of respiratory muscle training on cyclists between the ages of 18-45 did not significantly affect their anaerobic strength (Johnson, Sharpe, \& Brown, 2007).

Both groups showed significant increases in anaerobic strength during the trial period. Changes in anaerobic power as a result of respiratory-muscle training were significantly higher in the experimental and control groups. As well as respiratory muscle training, participants' being in the adolescent period is thought to contribute to the increase in anaerobic strength (Kasabalis, Douda, \& Tokmakidis, 2005).

The experimental group was observed to have higher aerobic strength than the control group after the $\mathrm{VO}_{2} \mathrm{Max}^{8}$ th week measurements. Similarly, in the study conducted on adult male and female cyclists, it was reported that respiratory muscle training increased oxygen consumption (Esposito, Limonta, Albert, Veicsteinas, \& Ferretti, 2010). It can therefore be said that respiratory muscle training helps to increase the oxygen use capacity.

In forced vital capacity (FVC) measurements, no statistical difference was observed between the groups in the 4th week measurements of the respiratory muscle training of the experimental group. However, in the 8th week measurements, a statistically significant difference was observed in the forced vital capacity of the experimental group. Normally, the developments in respiratory muscle training begin from the 4th week and the peak value starts from the 6th week (Kilding, Brown, \& McConnell, 2010).

In the study performed to determine the effects of different respiratory muscle training on fatigue, there was a significant difference in FEV1 and PEF values according to the measurement results of the respiratory muscles endurance training (Verges, Renggli, Notter, \& Spengler, 2009). While FVC, FEV1, PEF values were found to be 
statistically significant in an 8 week exercise in the study which examined the effects of respiratory muscle training on maximum oxygen consumption, no statistically significant difference was observed in FEV1/FVC values (Esposito, et al., 2010). According to the results of this study, at the end of the 8th week of respiratory muscle training which was given to the adolescent taekwondo athletes, FEV1 and FVC averages increased in favor of the experimental group.

No significant difference was observed for expiratory residual volume (ERV). In a study which examined the effects of respiratory muscle training on individuals that had breathing problems on maximum aerobic strength, it was revealed that the effects on ERV were significant (Esposito, et al., 2010). No study on ERV has been found in the studies of respiratory muscles training for athletes in the literature. While respiratory muscle training affects ERV values positively in the patients with respiratory disease, no effect was observed in the athletes. This may be because the athletes did not have any health problem in their lungs.

Respiratory muscle training for 8 weeks had no effect on inspiration residual volume (IRV). Similarly, in a study conducted on Kumite athletes, it was reported that 8-week respiratory muscle training did not affect IRV measurement results (Akgün, Pelvan, \& Duru, 2015). According to these results, it can be said that respiratory muscle training does not have a positive effect on IRV. Since the measurement time (12 seconds) of the maximum voluntary ventilation (MVV) was short, ATP and PCr were used for energy need (McArdle, Katch, \& Katch, 2001). In this study, the effect on MVV values is important during the respiratory muscle training. According to the results of the 6-week respiratory muscle training of male cyclists, MVV was observed to increase (Walker, et al., 2013). According to the result of the respiratory muscle training for Kumite athletes, a positive increase emerged in MVV (Kilding, et al., 2010). As in other studies, it was concluded that respiratory muscle training given to taekwondo athletes positively affects MVV.

After 8 weeks of respiratory muscle training, maximum inspiratory pressure was found to be affected in a positive way according to the results of inspiratory pressure measurements of the athletes. In a study conducted on rowing athletes, it was revealed that maximum inspiration pressure resulted in a significant difference in favor of the experimental group after the 8-week respiratory muscle training (Forbes, et al., 2011). Respiratory muscle training measurement has been performed in different branches of sports such as swimming, diving and cycling. According to the results of the measurements, respiratory muscle training affected maximum inspiration pressure in a positive way (HajGhanbari, et al. 2013). Since increasing maximum inspiration pressure is directly proportionate to the increase in average inspiration pressure, the increase in the average inspiration pressure is in favor of the experimental group.

In this study, inspiration strength increased in favor of the experimental group. It was seen that the respiratory muscle training on racer rowing athletes increased the average inspiration strength (Griffiths LA. 2010). In a study conducted to determine the effect of the respiratory muscle training on shuttle run, the training increased the maximum inspiration strength (Chatham, et al., 1999).

During the 8-week respiratory muscle training exercise session on the taekwondo athletes, average flow produced in the respiratory track was affected in a positive way due to the strength of the inspiration muscles. It was concluded that respiratory muscle training positively affected the average inspiratory flow in a 6-week study conducted to determine the effect of respiratory muscle training on fatigue in highly intensive intermittent runs (Tong, et al., 2008).

After the training, it was seen that the athletes' total inspiratory energy values produced from each breath in a session were positive on the experimental group. No inspiratory energy values were found in the respiratory muscle training. Respiratory muscle training is used for patients with respiratory disease. It has been shown that respiratory muscle training positively affects the inspiratory energy according to the results of different respiratory muscle training methods used for respiratory patients (Langer, et al., 2015).

There are some limitations in this study. Firstly, respiratory muscle training is being used for patients with respiratory disease for years, but it was only started to be used for athletes recently. Therefore, there are not enough studies in literature to compare and interpret the effects of respiratory muscle training on anaerobic power in athletes, and ERV and IRV parameters among slow vital capacity parameters of respiratory muscle training given to athletes. Secondly, there is a great difference in development and growth between individuals since the control and experimental groups included individuals between the ages of 12-17. If the study is to be conducted using individuals of the same age range and having the same physiologic characteristics, more precise results can be obtained.

According to the results of this study, respiratory muscle training has a positive effect on athletes as well as the patients with respiratory diseases. It was observed that the 8 -week respiratory muscle training contributed aerobic and anaerobic strength in adolescent taekwondo athletes.

According to the results obtained in this study, it is concluded that respiratory muscle training has a direct effect on aerobic and anaerobic power. It is thought that the data produced as a result of the study will contribute to the studies that will be done. 


\section{Acknowledgement}

This research was supported by Erciyes University Scientific Research Projects Unit by TYL-2016-7034 coded project. This study was presented as verbal presentation at the World Congress of Sport Sciences Researches. Koç M. , Sarıtaş N., "The Effect of Respiratory Muscle Training on Aerobic and Anaerobic Strength in Adolescent Taekwondo Athletes" The World Congress of Sport Sciences Researches, Manisa/Turkey 23-26 October 2017, pp.662-663).

\section{References}

Adıgüzel, N. S., \& Günay, M. (2016). The effect of eight weeks plyometric training on anaerobic power, counter movement jumping and isokinetic strength in 15-18 years basketball players, International Journal of Environmental and Science Education, 11(10), 3241-3250.

Adıgüzel, N. S., Karaçam, A., \& Kırkaltı, T. (2018). Core strength comparison of u16 football players according to the player's position. Gazi Journal of Physical Education and Sport Sciences; 23(3), 163-170.

Akgün, G., Pelvan, S. O., \& Duru, A. D. (2015). The effect of respiratory muscle trainig on physiological (respiratory) parameters of karate kumite athletes: pc139. Acta Physiologica, 215, 79.

Balbaloğlu, Ö. (2015). Pulmoner rehabilitasyonda egzersiz eğitimi. Bozok Tıp Dergisi, 55.

Bouhlel, E., Jouini, A., Gmada, N., Nefzi, A., Abdallah, K. B., \& Tabka, Z. (2006). Heart rate and blood lactate responses during Taekwondo training and competition. Science \& Sports, 21(5), 285-290. https://doi.org/10.1016/j.scispo.2006.08.003

Chatham, K., Baldwin, J., Griffiths, H., Summers, L., \& Enright, S. (1999). Inspiratory muscle training improves shuttle run performance in healthy $\quad$ subjects. Physiotherapy, 85(12), https://doi.org/10.1016/S0031-9406(05)61231-X

Esposito, F., Limonta, E., Alberti, G., Veicsteinas, A., \& Ferretti, G. (2010). Effect of respiratory muscle training on maximum aerobic power in normoxia and hypoxia. Respiratory physiology \& neurobiology, 170(3), $268-272$. https://doi.org/10.1016/j.resp.2010.02.004

Forbes, S., Game, A., Syrotuik, D., Jones, R., \& Bell, G. J. (2011). The effect of inspiratory and expiratory respiratory muscle training in rowers. Research in Sports Medicine, 19(4), 217-230. https://doi.org/10.1080/15438627.2011.608033

Fox, E., Bowers, R. W., \& Foss, M. L. (1999). Beden Eğitimi ve Sporun Fizyolojik Temelleri (Translate: Mesut Cerit.). Ankara: Bağırgan (In Turkey).

Griffiths, L. A. (2010). The application of respiratory muscle training to competitive rowing (Doctoral dissertation, Brunel University School of Sport and Education PhD Theses).

HajGhanbari, B., Yamabayashi, C., Buna, T. R., Coelho, J. D., Freedman, K. D., Morton, T. A., \& Reid, W. D. (2013). Effects of respiratory muscle training on performance in athletes: a systematic review with meta-analyses. The Journal of Strength \& Conditioning Research, 27(6), 1643-1663. https://doi.org/10.1519/JSC.0b013e318269f73f

Illi, S. K., Held, U., Frank, I., \& Spengler, C. M. (2012). Effect of respiratory muscle training on exercise performance in healthy individuals. Sports medicine, 42(8), 707-724. https://doi.org/10.1007/BF03262290

Johnson, M. A., Sharpe, G. R., \& Brown, P. I. (2007). Inspiratory muscle training improves cycling time-trial performance and anaerobic work capacity but not critical power. European journal of applied physiology, 101(6), 761-770. https://doi.org/10.1007/s00421-007-0551-3

Kasabalis, A., Douda, H., \& Tokmakidis, S. P. (2005). Relationship between anaerobic power and jumping of selected male volleyball players of different ages. Perceptual and motor skills, 100(3), 607-614.

https://doi.org/10.2466/pms.100.3.607-614

Kilding, A. E., Brown, S., \& McConnell, A. K. (2010). Inspiratory muscle training improves 100 and $200 \mathrm{~m}$ swimming performance. European journal of applied physiology, 108(3), 505-511. https://doi.org/10.1007/s00421-009-1228-X

Langer, D., Charususin, N., Jácome, C., Hoffman, M., McConnell, A., Decramer, M., \& Gosselink, R. (2015). Efficacy of a novel method for inspiratory muscle training in people with chronic obstructive pulmonary disease. Physical therapy, 95(9), 1264-1273. https://doi.org/10.2522/ptj.20140245

McArdle, W. D., Katch, F. I., \& Katch, V. L. (2001) Exercise physiology: Energy, nutrition and human performance; 518.

McConnell, A. K., \& Romer, L. M. (2004). Respiratory muscle training in healthy humans: resolving the controversy. 
Padula, C. A., \& Yeaw, E. (2007). Inspiratory muscle training: integrative review of use in conditions other than COPD. Research and theory for nursing practice, 21(2), 98-118. https://doi.org/10.1891/088971807780852039

Pine, M., \& Watsford, M. (2005). Specific respiratory muscle training for athletic performance. Sports Coach, 27(4), $1-4$.

Powers, S. K., \& Criswell, D. (1996). Adaptive strategies of respiratory muscles in response to endurance exercise. Medicine and Science in Sports and Exercise, 28(9), 1115-1122. https://doi.org/10.1097/00005768-199609000-00006

Scherer, T. A., Spengler, C. M., Owassapian, D., Imhof, E., \& Boutellier, U. R. S. (2000). Respiratory muscle endurance training in chronic obstructive pulmonary disease: impact on exercise capacity, dyspnea, and quality of life. American Journal of Respiratory and Critical Care Medicine, 162(5), 1709-1714. https://doi.org/10.1164/ajrccm.162.5.9912026

Spear, B. A. (2002). Adolescent growth and development. Journal of the Academy of Nutrition and Dietetics, S23. https://doi.org/10.1016/S0002-8223(02)90418-9

Stamford, B. (1983). The Results of Aerobic Exercise. The Physician and sports medicine, 11(9), 145. https://doi.org/10.1080/00913847.1983.11708642

Thompson, W. R., \& Vinueza, C. (1991). Physiologic profile of taekwondo black belts. Research in Sports Medicine: An International Journal, 3(1), 49-53.

Tong, T. K., Fu, F. H., Chung, P. K., Eston, R., Lu, K., Quach, B., \& So, R. (2008). The effect of inspiratory muscle training on high-intensity, intermittent running performance to exhaustion. Applied physiology, nutrition, and metabolism, 33(4), 671-681. https://doi.org/10.1139/H08-050

Verges, S., Renggli, A. S., Notter, D. A., \& Spengler, C. M. (2009). Effects of different respiratory muscle training regimes on fatigue-related variables during volitional hyperpnoea. Respiratory physiology \& neurobiology, 169(3), 282-290. https://doi.org/10.1016/j.resp.2009.09.005

Walker, D. J., Ertl, T., Walterspacher, S., Schlager, D., Roecker, K., Windisch, W., \& Kabitz, H. J. (2013). Respiratory muscle function during a six-week period of normocapnic hyperpnoea training. Respiratory physiology \& neurobiology, 188(2), 208-213. https://doi.org/10.1016/j.resp.2013.05.005

\section{Copyrights}

Copyright for this article is retained by the author(s), with first publication rights granted to the journal.

This is an open-access article distributed under the terms and conditions of the Creative Commons Attribution license which permits unrestricted use, distribution, and reproduction in any medium, provided the original work is properly cited. 